\title{
REALISTIC REQUIREMENTS \\ FOR UNBONDED \\ POST-TENSIONING TENDONS
}

Kenneth B. Bondy

Atlas Prestressing Corp.

Panorama City, California
There is a considerable difference between the physical capabilities of a prestressing tendon in a testing machine and the physical conditions which can be imposed upon that tendon when it is installed and left unbonded in a concrete structure. For example, the maximum force which can be developed in an unbonded tendon in an actual structure is about 90 percent of the rated $^{*}$ ultimate tendon force, yet most specifications require that the anchorages develop 100 percent of the rated strength. The maximum total elongation possible in an unbonded tendon in a structure is in the order of 1.0 percent, yet specifications require between 2 and 3 percent. Performance specifications for unbonded post-tensioning tendons have, thus, consistently been written solely on the basis of "testing machine" capabilities, rather than actual structural requirements. They are based on what the tendon can do, rather than on what it actually has to do. It is extremely important that the designer of unbonded posttensioned structures recognizes the difference between the capabilities

* Rated strength = guaranteed ultimate strength of the prestressing steel (see References 1-3 for typical specifications). and the requirements. Over-reliance on ultra-conservative tendon specifications can shift the designer's attention from more important aspects of the design and detailing of unbonded structures, in effect causing him to "miss the forest for the trees".

Criteria for unbonded post-tensioning tendons have been established in three general performance areas-static strength, static ductility, and dynamic strength. It is the purpose of this paper to discuss each of these performance areas, and to demonstrate the differences which can exist between the common performance specifications for unbonded tendons and the maximum performance conditions which can be imposed upon the tendons in an actual structure.

\section{STATIC STRENGTH}

For static tendon strength, specifications for unbonded post-tensioning tendons generally require that the tendon anchorages develop 100 percent of the rated strength of the prestressing steel which they anchor. This is a good basic requirement, founded on the sound engineering principle that a connection should not be the weak link in a member. When viewed in the light of the maximum force that may possibly be developed in the prestress- 
A detailed review of current specifications for unbonded posttensioning tendons, relative to performance in building structures, points out those areas where practical re-evaluation of specifications should be made and good engineering judgment followed.

ing tendon in a structure, however, this requirement appears to be conservative for members designed according to current codes.

In a tendon which has been grouted after stressing (assuming that the grouting job actually results in complete bonding of the tendon), the change in strain in the prestressing steel at any point in the member under load is equal to the change in strain in the concrete immediately surrounding the tendon. The force in a bonded tendon, therefore, is a function of the external moment in the member, and the higher the moment the higher the force in the bonded tendon.

This is not the case in an unbonded tendon. Because the tendon is unbonded, local strains distribute throughout the entire length of the tendon, and high local moments in the member do not produce a significant proportional increase in tendon force. Thus, except for the local effect of friction between the tendon and the concrete, the only way to significantly increase the force in an unbonded tendon is to increase the overall length of the concrete member containing the tendon. Since the frictional effects are usually small, and the increase in length of a concrete member due to transverse deflection is a second-order effect, it naturally follows that for all but the most lightly prestressed members, it is physically impossible to increase the force in the unbonded tendon to any great degree. This is both a disadvantage and an advantage for unbonded tendons.

From one standpoint, it is a disadvantage because, due to the reduced ultimate tendon force, additional tendons or mild steel must occasionally be provided to satisfy ultimate strength requirements. This disadvantage is, however, only academic because the additional material required for normal usage in building construction is not enough to economically justify grouting the tendons.

On the other hand, the fact that high ultimate tendon forces are not possible in unbonded tendons provides them with a significant advantage over bonded steel. It means that it is virtually impossible to develop enough force in an unbonded tendon to fail it in a concrete structure. This fact has long been recognized by American building codes. For example, Equation (26-7) in the 1963 ACI Building Code (ACI 31863) expresses the ultimate stress in an unbonded tendon as follows:

$$
f_{s u}=f_{s e}+\Delta f_{s}
$$

where $f_{s u}$ is the ultimate tendon 


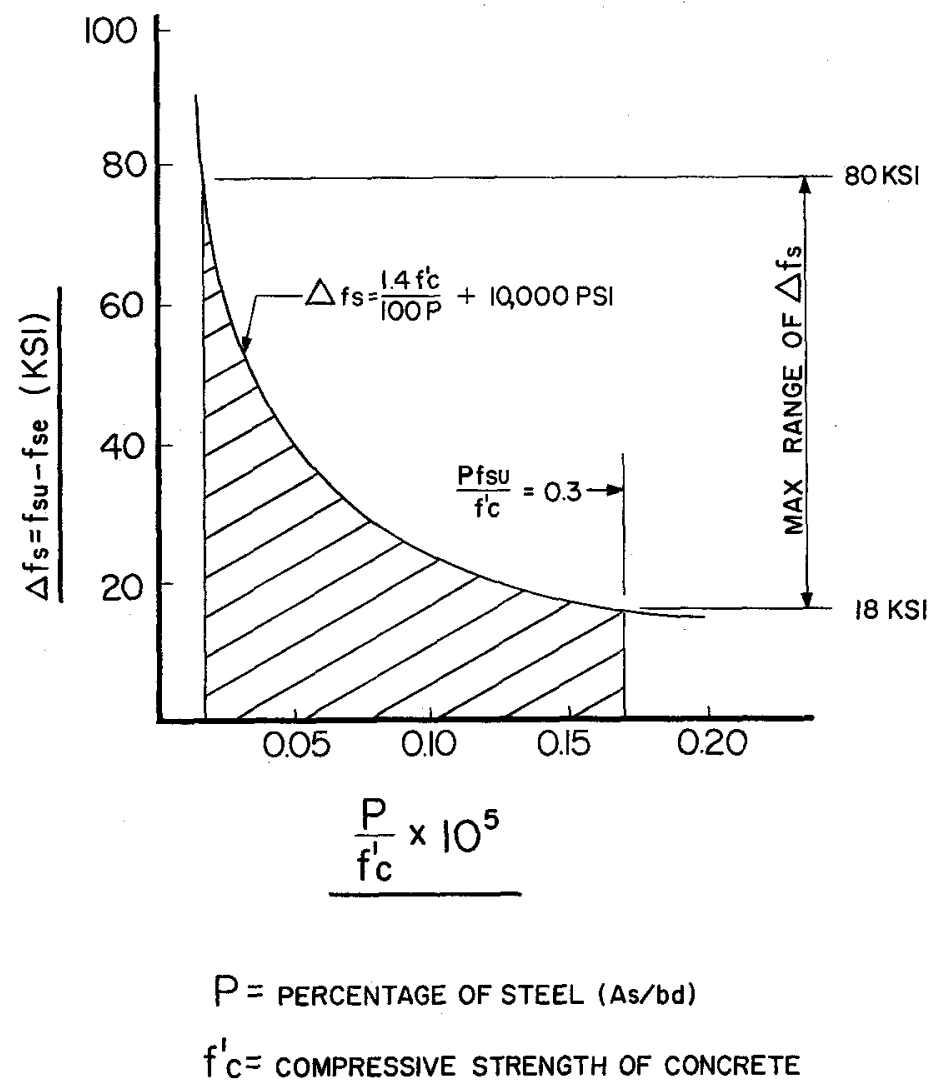

Fig. 1. Variation in stress increase with steel percentage

stress, $f_{s e}$ is the effective or working tendon stress, and $\Delta f_{s}$ is the increase in tendon stress from effective to ultimate. Without additional technical data, ACI 318-63 limits $\Delta f_{s}$ to a value of 15,000 psi. For a common 270-ksi post-tensioning strand with an effective stress of $162 \mathrm{ksi}$, the ultimate tendon stress allowed by the Code is only $162+15$ or $177 \mathrm{ksi}$. Thus, for ultimate strength design, the Code limits the design ultimate stress to only 66 percent of the rated strength of the tendon, considerably below the 100 percent that the an- chorages must develop according to the specifications.

It is a well known fact that the $15 \mathrm{ksi}$ limitation imposed by the Code is conservative in many instances. In other words, in most concrete members it is possible to develop more than $15 \mathrm{ksi}$ for $\Delta f_{s}$. The question may well be asked, then, "How much force can actually be developed in an unbonded tendon?"

This question may be answered by examining the results of tests performed on concrete members prestressed with unbonded tendons ${ }^{(4-15)}$. 
Dr. Alan H. Mattock of the University of Washington has derived an empirical equation for $\Delta f_{s}$ in unbonded tendons which closely matches all existing test data $^{(t)}$ :

$$
\Delta f_{s}=\frac{1.4 f_{c}^{\prime}}{100 p}+10,000
$$

This equation is plotted in Fig. 1. It should be noted that the equation was developed from the results of tests on simple-span beams with constant section. Recent tests ${ }^{(t)}$ indicate that the equation may shightly overestimate the tendon force for continuous members, but it is still much more accurate than the current $\Delta f_{s}$ $=15 \mathrm{ksi}$.

As can be seen from Fig. 1, as the percentage of prestressing steel increases, the ultimate tendon stress decreases; conversely, the maximum possible tendon stresses occur in the most lightly post-tensioned members. The shaded area of the curve represents the range of $\Delta f_{s}$ values which occur in practice. The minimum value is determined from Sect. 2609 (a) of ACI 318-63 which limits the maximum value of $p f_{s u} / f_{c}^{\prime}$ to 0.3 . Thus,

$$
\begin{aligned}
& \frac{p}{f_{c}^{\prime}}=\frac{0.3}{f_{s H}}=\frac{0.3}{1.77 \times 10^{5}} \\
& \frac{p}{f_{c}^{\prime}}=0.17 \times 10^{-5}
\end{aligned}
$$

The maximum value can be determined by considering the most lightly reinforced member commonly designed, which is the monolithic T-beam commonly used in longspan garage construction. The lowest $p / f_{c}^{\prime}$ values for these members are in the order of $0.02 \times 10^{-5}$. Thus, actual ultimate tendon stresses in structures can range between $180 \mathrm{ksi}$ for heavily reinforced members and $242 \mathrm{ksi}$ for lightly reinforced members. These ranges represent 67 and
90 percent of the rated steel ultimate strength, respectively.

With these data in mind, it seems reasonable then to require the tendon anchorages to develop, say, 95 percent of the rated strength of the prestressing steel, and to limit the maximum ultimate design stress to about 90 percent of ultimate capacity. This assumes, of course, that a rational equation such as Mattock's is used to derive the design ultimate stress, rather than the conservative one presently in ACI 318-63. Designed according to the present ACI code, with $f_{s u}=177 \mathrm{ksi}$, a tendon anchorage will be adequate if it develops only 80 percent of rated ultimate strength (216 ksi), ${ }^{*}$ and conservative if it develops 100 percent (270 ksi).

\section{STATIC DUCTILITY}

Maximum strains. Along with strength requirements, specifications for unbonded tendons generally include a ductility requirement. This ductility requirement is usually expressed as a minimum percent elongation in a 10-ft. tendon under total load. Ref. 1, which requires a 2.5 percent elongation, states, "The requirement for percent elongation is included because it is important that the anchorage used not damage the tendons and lead to a failure at an elongation below specified. The tendon should elongate appreciably to avoid the possibility of a brittle type failure".

* This corresponds to the maximum stress permitted by the code under any condition, i.e., the temporary initial jacking stress of $0.8 \mathrm{f}^{\prime}{ }^{\prime}(216 \mathrm{ksi})$. Note that this initial stress is actually greater than the allowable ultimate stress of $177 \mathrm{ksi}$, meaning that each unbonded tendon is proof-tested (at time of stressing) to a stress level which is some 20 percent higher than that required to develop the ultimate flexural strength of the member. 
While the above statement is true in a qualitative sense, the quantitative requirement of 2.5 percent is questionable, even though it is possible to achieve it in a testing machine with most existing tendon-anchorage systems. As will be seen below, the maximum possible total elongation for an unbonded tendon in an actual structure is in the order of 1.0 percent, less than half of that required by even the most liberal of specifications*.

First, consider the simple case of axial elongation in a beam to determine the magnitude of tendon elongation that is possible. The maximum allowable working stress in a typical unbonded tendon with an ultimate stress of 270,000 psi is 162 ,$000 \mathrm{psi}$, or 60 percent of ultimate. At this working stress level, the tendon elongation is

$$
\begin{aligned}
\epsilon_{s} & =\frac{\sigma}{E}=\frac{162,000}{27,500,000} \\
& =0.0059 \mathrm{in} . / \mathrm{in} .(0.59 \%)
\end{aligned}
$$

The average compressive strain in the concrete is, of course, a function of the compressive stress induced by the tendons. Using a typical compression value of 300 psi, the average compressive strain in the concrete $^{*}$ is

$$
\begin{aligned}
\epsilon_{o} & =\frac{\sigma}{E}=\frac{300}{2,400,000} \\
& =0.000125 \mathrm{in} . / \mathrm{in} .(0.0125 \%)
\end{aligned}
$$

From this starting point, assume that the entire concrete member begins to lengthen. (It is somewhat hard to imagine what could be caus-

* There is some difference in published specifications for tendon elongation but all are between 2 and 3 percent.

* Assume lightweight concrete to maximize compressive strain. ing this lengthening, but since this is the only way to significantly increase the tendon force, we will assume it is happening, without further explanation). As the member gets longer, the unbonded tendon gets longer also, increasing both force and elongation in the tendon. This elongation continues until either the tendon or the concrete fails in tension. Of course, the concrete will fail first when the total strain causes a tensile stress equal to the modulus of rupture of the concrete. Assuming 4000 -psi concrete, the modulus of rupture is

$$
f_{r}=7.5 \sqrt{f_{c}^{\prime}}=475 \text { psi }
$$

and the strain is

$$
\begin{aligned}
\epsilon_{c} & =\frac{475}{2,400,000} \\
& =0.0002 \text { in. } / \text { in. }(0.02 \%)
\end{aligned}
$$

The total tendon strain is the sum of the initial strain, the strain to overcome the initial concrete compression, and the strain to reach the modulus of rupture:

$$
\begin{aligned}
\epsilon_{s}(\text { total }) & =0.59+0.0125+0.020 \\
& =0.6225 \%
\end{aligned}
$$

Thus, when the entire concrete section has failed in tension, the total tendon elongation is only $5 / 8$ of 1 percent.

It is, of course, possible to realize greater elongation in the tendon by transverse deflection of the beam. For example, consider the beam in Fig. 2. The working stress in the tendons under load is 162,000 psi. It is of interest to calculate the tendon elongation required to develop the ultimate tendon stress of $177,000 \mathrm{psi}$ as defined in ACI 318-63. This elongation is

$$
\begin{aligned}
\epsilon_{s} & =\frac{\sigma}{E}=\frac{177,000}{27,500,000} \\
& =0.006436 \mathrm{in} . / \mathrm{in} .(0.6436 \%)
\end{aligned}
$$




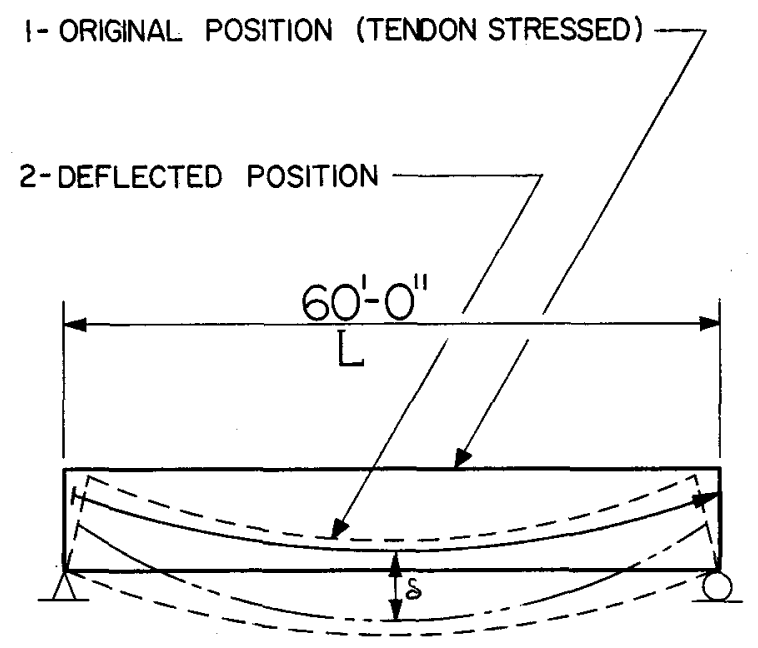

BY PROPERTIES OF PARABOLAS

$$
\begin{aligned}
L_{2}-L_{1}=\triangle & =\frac{0.222 \delta^{2}}{L} \\
\text { WHERE } L_{1} & =\text { ORIGINAL TENDON LENGTH (INCHES) } \\
L_{2} & =\text { FINAL TENDON LENGTH (INCHES) } \\
\triangle & =\text { INCREASE IN TENDON LENGTH (INCHES) } \\
\delta & =\text { BEAM DEFLECTION (INCHES) } \\
L & =\text { BEAM LENGTH (FEET) }
\end{aligned}
$$

Fig. 2. Deflection of simple span beam under load

The beam deflection required to produce this elongation is

$$
\begin{aligned}
\boldsymbol{\sigma} & =\sqrt{\frac{720(0.006436-0.0059) \times 60}{0.222}} \\
& =10.2 \mathrm{in} .
\end{aligned}
$$

Thus, it is seen that, under the present ACI code, only about 0.64 per- cent elongation is actually required to develop the maximum allowable ultimate tendon stress.

Finally, what about the maximum possible tendon elongation which could ever be expected in an unbonded tendon? We can set an absolute upper bound on this value by considering the maximum possible 
tendon stress and correlating this with elongation from a stress-strain curve. Fig. 1 tells us that the maximum stress which can be expected is $162+80$ or $242 \mathrm{ksi}$. If we assume that this stress is constant throughout the length of the tendon, a 270ksi strand stress-strain curve indicates that the tendon elongation at 242 ksi will be slightly less than 1 percent. At this stress (90 percent), the steel will have just yielded.

In summary, under the present ACI Building Code, a tendon elongation requirement of only 0.75 percent would be sufficient to develop the ultimate stress with reserve ductility available. When a more realistic ultimate tendon stress equation is adopted, this author feels that the elongation specification should be in the order of 1.5 percent. It should be pointed out that in recent tests at the University of Washington, in extremely lightly reinforced unbonded beams, ultimate tendon elongations of 1.9 percent were achieved. However, these high values occurred at ultimate loads some 30 percent greater than the design ultimate load; 1.5 percent elongation at design ultimate would have been sufficient.

Minimum strains (stress reversal). The above discussion concerns maximum tendon strains. How about minimum strains, which are important considerations in potential stress reversal situations? As developed above, the effective strain in the tendon under working load is 0.0059 in./in. and the corresponding concrete strain is $0.000125 \mathrm{in}$./in.

The only way to change the steel strain in the tendon is to change the length of the member and, assuming the member becomes shorter (reducing the steel strain), the concrete will crush when the concrete strain reaches $\epsilon_{c}=0.003$. The corresponding change in steel strain will be

$$
\begin{aligned}
\Delta \epsilon_{s} & =0.003-0.000125 \\
& =0.02875 \mathrm{in} . / \mathrm{in} .
\end{aligned}
$$

The steel strain at failure of the concrete will be

$$
\begin{aligned}
\epsilon_{s} & =0.0059-0.002875 \\
& =0.003025 \mathrm{in} . / \mathrm{in} .
\end{aligned}
$$

The corresponding stress in the steel at this strain is

$$
\begin{aligned}
\sigma_{s}= & 0.003025 \times 27,500,000 \\
= & 83,000 \text { psi }\left(31 \% \text { of } f_{s}^{\prime}\right. \\
& \text { or } \left.51 \% \text { of } f_{s e}\right)
\end{aligned}
$$

Thus, the minimum possible tendon stress, at the time of concrete failure, is about 30 percent of the ultimate steel stress and about 50 percent of the working stress. It is seen that stress reversal in the tendon is impossible without destroying the concrete. For the tendon stress to be reduced to zero, the concrete compressive strain would have to be

$$
\begin{aligned}
\epsilon_{c} & =0.0059+0.000125 \\
& =0.006025 \mathrm{in} . / \mathrm{in} .
\end{aligned}
$$

or over twice the ultimate concrete compressive strain.

This fact can be envisioned by considering a typical 60 -ft. long posttensioned beam. The effective tendon elongation will be approximately 4.5 in. In order to decrease the tendon force to zero the member would have to become 4.5 in. shorter! Obviously, this is impossible, and its consideration should dispel the fears of those engineers who are concerned with stress reversal in unbonded tendons.

\section{DYNAMIC STRENGTH}

A very common specification for unbonded tendons requires that they 
be subjected to a 500,000 -cycle fatigue test without failure, cycling between 60 and 66 percent of the rated steel stress ${ }^{(2,3)}$. For $270-\mathrm{ksi}$ strand, this means 500,000 cycles between $162 \mathrm{ksi}$ and $178 \mathrm{ksi}$. This test is intended to demonstrate the response of the tendon to the many minor vibrations which may occur in the life of a building structure.

In evaluating this test, first consider that $162 \mathrm{ksi}$ is the effective, or working stress, while $178 \mathrm{ksi}$ is, per the current ACI Building Code, the ultimate tendon stress. Thus, the test means cycling the tendon 500,000 times between its service load condition and its ultimate load condition!

To examine what this would mean to a beam with unbonded tendons, consider the beam shown in Fig. 2. Under service load, the tendons will be stressed to $162 \mathrm{ksi}$. In order to increase the stress to $178 \mathrm{ksi}$, the beam must deflect until the tendon elongates an additional amount

$$
\begin{aligned}
\Delta & =\frac{\sigma L}{E} \\
& =\frac{(178-162) 60 \times 12 \times 1000}{27,500,000} \\
& =0.42 \mathrm{in} .
\end{aligned}
$$

To lengthen the tendon $0.42 \mathrm{in}$. the beam must deflect (by properties of parabolas) an amount

$$
\sigma=\sqrt{\frac{0.42 \times 60}{0.222}}=10.7 \mathrm{in} .
$$

Thus, for the tendon to feel the stress variations required by the specification, the beam would have to be deflected from zero to almost one foot at midspan, not once, but 1/2 million times! Any tendon capable of surviving this cyclic requirement is most capable of resisting normal building vibrations. It is indeed questionable whether the beam concrete itself could survive this dynamic test.

A more realistic dynamic requirement, and one which approximates seismic actions, is that which appears in Sect. 4.2.4 of the ACI-ASCE Joint Committee 423 report $^{(1)}$. This recommendation states that the tendon must withstand 50 cycles of loading with the following stress range (corresponding to percentage of rated strength):

$$
\Delta \sigma=60 \pm \frac{2000}{L+100}
$$

The extreme range $(L=0)$ is then between 40 and 80 percent of the ultimate steel strength. This is an excellent and realistic requirement, since the maximum possible stress range for any unbonded tendon, as seen previously, is between 30 and 90 percent of ultimate. Fifty cycles between 40 and 80 percent thus approximates a reasonable number of seismic cycles and covers almost the entire possible tendon stress range.

In summary, the 50-cycle high stress range requirement is very realistic and appropriate and should be in all specifications for tendons in seismic zones. The 500,000-cycle fatigue test is unrealistic in approximating normal building vibratory conditions, however sufficient data do not yet exist which can establish a lower bound for this test. Until such data are developed, it is recommended that the present specification be used, with judgment. This is one performance area where conservatism is advisable.

\section{CLOSURE}

The purpose of this paper is not to recommend an immediate liberalization of all specifications for unbonded post-tensioning tendons. Lib- 
eralization will come in time, as engineers become more and more familiar with unbonded post-tensioned structures. Such is the case with all new types of construction materials and methods. From a practical standpoint, a conservative specification does not become objectionable until it reaches the point where it causes a building owner to spend money unnecessarily. Conservative as they may be, current specifications for unbonded post-tensioning tendons have had little economic effect on purchasers of unbonded, post-tensioned structures, because all of the commonly marketed unbonded systems do satisfy the specifications.

The real purpose of this paper will be well served if it points out to the designer that he is merely wasting his time by worrying whether the tendon system can develop 96 , 98 or 100 percent of the rated strength of the steel; or whether the tendon can develop 2 or 3 percent total elongation under load. These numbers are insignificant because none of them are ever felt by the tendon in an actual structure. Conversely, the designer should not be lulled into a false sense of security if he knows that the tendon system will develop 100 percent of the strength of the steel, or 3 percent total elongation, because these facts alone will not guarantee a properly performing structure.

By far, the most important considerations in the performance of an unbonded post-tensioned concrete structure are the overall structural design and detailing of the members, considering the interaction and contribution of each of the three basic materials: concrete, prestressing steel, and mild reinforcing steel. Of exceptional importance is the proper proportioning and placement of the auxiliary mild reinforcing steel, both in tensile zones of the member and in the anchorage regions. Now that post-tensioned concrete construction with unbonded tendons is a wellestablished structural media, it appears that designers should spend less time debating tendon properties which are possible to achieve only in testing machines, and devote this time to factors which are considerably more important in producing safe, serviceable unbonded post-tensioned structures.

\section{REFERENCES}

1. ACI-ASCE Joint Committee 423, "Tentative Recommendations For Concrete Members Prestressed with Unbonded Tendons," ACI Journal, Proc. Vol. 66, No. 2, February 1969, pp. 81-88.

2. ACI Committee 301, "Specifications For Structural Concrete For Buildings," ACI Manual of Concrete Practice, Part 2, 1968, Chapter 15, pp. 301-45 to 301-50.

3. PCI Post-Tensioning Committee, "Tentative Specification For Post-Tensioning Materials," in preparation.

4. Mattock, Alan H., Yamazaki, Jun and Kattula, Basil T., "A Comparison of the Behavior of Post-Tensioned Prestressed Concrete Beams With and Without Bond," Structures \& Mechanics Report SM69-3, Department of Civil Engineering, University of Washington, 1969.

5. Burns, Ned H. and Pierce, David M., "Strength \& Behavior of Prestressed Concrete Members With Unbonded Tendons," PCI Journal, October 1967, pp. 15-29.

6. Nawy, Edward G. and Salek, Franklin, "Moment-Rotation Relationships of Non-Bonded Post-Tensioned I- and TBeams," PCI Journal, August 1968, pp. 40-55.

7. Freyermuth, Clifford L. and Shoolbred, Robert A., "Post-Tensioned Prestressed Concrete," Portland Cement Association, Skokie, Illinois, 1967.

8. Grow, J. B. and Vanderbilt, M. D., "Shear Strength of Prestressed Lightweight Aggregate Concrete Flat 
Plates," PCI Journal, August 1967, pp. 18-28.

9. Feldman, A., "Bonded and Unbonded Prestressed Concrete Beams Failing in Flexure," University of Illinois, Progress Report of Investigation of Prestressed Concrete for Highway Bridges, for Bureau of Public Roads, June 1954.

10. Janney, J. R., Hognestad, E., and McHenry, D., "Ultimate Flexural Strength of Prestressed and Conventionally Reinforced Concrete Beams," ACI Journal, Proc. Vol. 52, February 1956, pp. 601-620.

11. Scordelis, A. C., Lin, T. Y., and May, H. R,, "Flexural Strength of Prestressed Concrete Beams at Transfer," Proceedings World Conference on Prestressed Concrete, San Francisco, 1957.

12. Warwaruk, J., Sozen, M. A., and Siess, C. P., "Strength and Behavior in Flex- ure of Prestressed Concrete Beams," Engineering Experiment Station, Bulletin No 464, University of Mlinois, 1962.

13. Scordelis, A. C., Pister, K. S., and Lin, T. Y., "Strength of a Concrete Slab Prestressed in Two Directions," ACI Journal, Proc. Vol. 53, September 1956, pp. 241-256.

14. Scordelis, A. C., Lin, T. Y., and May, H. R., "Shearing Strength of Prestressed Lift Slabs," ACI Journal, October 1958, pp. 485-506.

15. Lin, T. Y., Scordelis, A. C., and Itaya, R., "Behavior of a Continuous Slab Prestressed in Two Directions," ACI Journal, Proc. Vol. 56, December 1959, pp. 441-459.

16. ACI Committee 318, "Building Code Requirements For Reinforced Concrete," American Concrete Institute (ACI 318-63), June 1963. 